\title{
Associations between the Rorschach Ego Impairment Index and Measures on Intrapsychic and Interpersonal Functioning
}

\author{
Jaakko Stenius', Olavi Lindfors'2, Risto Antikainen', Jarl Wahlström³, \\ Laura Sares-Jäske², Paul Knekt ${ }^{2}$ \\ ${ }^{1}$ Department of Psychiatry, Kuopio University Hospital, Kuopio, Finland \\ ${ }^{2}$ National Institute for Health and Welfare, Helsinki, Finland \\ ${ }^{3}$ Department of Psychology, University of Jyväskylä, Jyväskylä, Finland \\ Email: jaakkosten@gmail.com
}

How to cite this paper: Stenius, J., Lindfors, O., Antikainen, R., Wahlström, J., Sares-Jäske, L. and Knekt, P. (2018) Associations between the Rorschach Ego Impairment Index and Measures on Intrapsychic and Interpersonal Functioning. Open Journal of Psychiatry, 8, 1-19.

https://doi.org/10.4236/ojpsych.2018.81001

Received: October 6, 2017

Accepted: November 14, 2017

Published: November 17, 2017

Copyright $\odot 2018$ by authors and Scientific Research Publishing Inc. This work is licensed under the Creative Commons Attribution International License (CC BY 4.0).

http://creativecommons.org/licenses/by/4.0/

(C) (i) Open Access

\begin{abstract}
The Rorschach Ego Impairment Index-2 (EII-2) has shown considerable validity as a measure of personality disturbance. However, few studies have been conducted on the associations between the EII- 2 and measures related to ego strength and interpersonal capacities in mood and anxiety disorder patients. This study examined the strength of associations between the EII- 2 and its subcomponents with measures of psychological suitability for psychotherapy, personality functioning, and interpersonal problems. A total of 315 outpatients with mood or anxiety disorders were assessed with the Rorschach Comprehensive System (RCS), comprising the EII-2, the Suitability for Psychotherapy Scale (SPS), the Inventory of Interpersonal Problems (IIP-64), and the Quality of Object Relations Scale (QORS), as part of a pre-treatment evaluation. The relatively weak associations found in the study between the EII-2 and the other measures were mostly in the hypothesized direction and often modified by personality pathology. Of the EII-2 subcomponents, the Good Human Representation (GHR) variable was associated with the SPS. The subcomponent Critical Contents were associated with the IIP and the subcomponent WSum6 with the IIP and QORS. Further research is needed to clarify whether the EII-2 has incremental validity in predicting the treatment outcome and alliance in comparison to interview-based and self-report measures.
\end{abstract}

\section{Keywords}

Rorschach, Ego Impairment Index, Suitability for Psychotherapy Scale, Inventory of Interpersonal Problems, Quality of Object Relations Scale 


\section{Introduction}

The assessment of relatively stable personality characteristics such as ego strength and interpersonal functioning with clinical interviews and self-reported questionnaires has been found to be important when evaluating indications and suitability for psychotherapy [1] [2] [3]. The accuracy of the assessment of intrapsychic and interpersonal functioning is suggested to be improved when based on a multimethod assessment approach that incorporates information obtained from both explicit assessment methods, such as clinical interviews and self-report measures, and performance-based methods, such as the Rorschach method [4] [5]. For this reason, understanding of the associations between these complementary assessment methods is important. However, although the Rorschach method is widely used in treatment planning, knowledge of the potential utility of the Rorschach Ego Impairment Index in relation to self-reported and interview-based measures is incomplete.

The Ego Impairment Index (EII) [6], (EII-2) [7] is a theoretically based composite Rorschach measure, designed to provide data regarding reality testing, reasoning processes, defensive functions, and the quality of object relationships [7]. It thus measures the underlying ego organization and the capacity to meet internal and external demands and stressors [6]. Previous studies have demonstrated the ability of the EII-2 to reflect the continuum of psychiatric severity [8] and to distinguish between patient groups representing a diverse range of impairment, e.g., inpatients vs. outpatients [9] and patients with psychotic disorder vs. non-patients [10]. However, previous studies on the associations between the EII and self-report-based assessment of ego strength, e.g., the Ego Strength and Schizophrenia scales, as well as the average elevation of the scores of the Minnesota Multiphasic Personality Inventory (MMPI) [11], have inconsistently shown either weak or no associations [9] [12] in the few heterogeneous inpatient and outpatient samples. In a recent study focusing on depressive and anxiety disorder patients and the severity spectrum between neurosis and higher-level borderline personality organization, the EII-2 and its thought disorder component, WSum6, were found to be consistently, although relatively modestly, associated with the Level of Personality Organization (LPO) interview scale and both similarly associated with psychiatric diagnoses, symptoms, and psychiatric history, while also indicating their relative independence as measures of the severity of psychopathology [13]. However, relatively little attention has been focused on the more specific associations of the EII-2 with other personality assessment methods used in psychotherapy assessment for this patient group.

The Quality of Object Relations Scale (QORS) [14] and the Suitability for Psychotherapy Scale (SPS) [1] are interview-based measures, while the Inventory of Interpersonal Problems (IIP-64) [15] is a self-report measure that is used to assess intrapsychic and interpersonal functioning, which is relevant for optimal treatment choice, beyond the assessment of psychiatric severity, which is based on the diagnosis. The QORS provides information on the object relational pa- 
thology and the SPS on the personality and interpersonal dispositions of patients, i.e. a global assessment of suitability for psychotherapy, ego strength, the self-observing capacity, and the nature of problems. They have been shown to be useful in treatment planning [1] [16] [17] [18] [19]. Likewise, the IIP has been shown to reliably measure overall interpersonal difficulties, which is also relevant for ego impairment and assessment of the need for psychotherapy [15] [20] [21]. As a measure of personality disturbance that assesses a number of areas of intrapsychic and interpersonal functioning, it is reasonable to expect that the EII-2 would be associated with these measures. However, as far as the authors are aware, no studies have been published on the associations between EII-2 and the QORS, SPS, or IIP.

Associations between independent assessment methods, such as self-reports, clinical interviews, and performance-based assessment methods, assessing similar constructs, have generally been shown to be low to moderate [5] [22], thus indicating that any single assessment method only provides a partial representation of the characteristics it intends to measure, being sensitive to different domains of personality [5]. By analogy, the Rorschach, as a performance-based and indirect method, is a distinctively different type of measure from interview and self-report measures, the SPS, QORS, and IIP, thus enabling these to examine different facets of the targeted phenomena. Information on the extent of their convergence as measures of psychological functioning is needed to improve understanding of these constructs and to more adequately apply the methods in clinical assessment.

There are individual differences in the capacity to recognize aspects of personality functioning and psychological difficulties, one major source of variability being the level of personality organization. Accordingly, the presence of personality disorder is known to affect an individual's interpersonal functioning and the manifestation of problems in many ways, as well as reducing the ability to recognize and verbalize psychological problems [4], thus possibly forming a potential source of bias in research focusing on associations between different types of assessment methods. Therefore, in order to eliminate the possible biasing effect of personality disorder, the associations need to be examined separately in participants with or without personality disorder.

The objective of the present study was to examine the strength of associations between the EII-2 and three measures of intrapsychic and interpersonal functioning, the SPS, QORS, and IIP. Based on previous research, we hypothesized that the EII-2 would be consistently, but relatively weakly associated with a poorer suitability for psychotherapy, a lower quality of object relationships and higher values for reported interpersonal problems.

\section{Methods}

\subsection{Patients}

This study was based on baseline data from the Helsinki Psychotherapy Study, in 
which a total of 326 outpatients with depressive or anxiety disorder (DSM-IV; American Psychiatric Association, 1994) participated in a randomized trial comparing two short-term and one long-term psychotherapy [23] [24]. The patients, aged 20 - 46 years, were also required to have a longstanding ( $>1$ year) disorder causing work disability and they had to be estimated on a psychodynamic scale of suffering from neurosis to high-level borderline disorder. Patients were excluded from the study on the basis of the severity of the disorder and type of co-morbidity, namely the presence of psychotic disorder, bipolar I disorder, severe personality disorder (DSM-IV cluster A personality disorder and/or lower level borderline personality organization), adjustment disorder, substance abuse, organic brain disease or other diagnosed severe organic disease, and mental retardation. Individuals who had undergone psychotherapy within the previous two years and psychiatric health employees were also excluded. The final study population consisted of 315 patients, since 11 patients giving interpretatively invalid Rorschach Comprehensive System (RCS) protocols ( $<14$ responses) were excluded [13]. Thus, the included protocols fulfilled the requirements for the number of responses and their interpretive value [25]. Approval for the study was obtained from the ethics council of Helsinki University Central Hospital. All patients provided written informed consent before entering the study. The patients were relatively young adults and predominantly female, and about one-fourth of them had completed a university degree (Table 1). Over half of the patients suffered from mood disorder, about one-sixth from anxiety disorder, and over one-fourth from co-morbid mood and anxiety disorder. Personality disorder was diagnosed in almost one-fifth of the patients.

\subsection{Measures}

The patients were assessed at baseline via three interviews, self-report questionnaires, and psychological testing. The manualized, semi-structured interviews were conducted by experienced and trained clinical interviewers. The interviews were based on a modification of Kernberg's Structural Interview [26], and comprised exploration of current problems and the quality of object relations [14] [27], psychological suitability for psychotherapy [1], as well as the setting of diagnoses [23].

\subsubsection{The Rorschach Ego Impairment Index (EII-2)}

The RCS was administered and scored in accordance with standard guidelines [25]. The administration and coding procedures are described in more detail elsewhere [13]. For the purpose of inter-rater agreement, 20 protocols were randomly chosen and rescored independently by one psychologist. Intraclass correlation (ICC) was used to calculate the inter-rater reliability of the EII-2 and its subcomponents. All ICC coefficients were excellent.

The EII- 2 was derived from the RCS scores according to an algorithm based on several scores. These were the number of the responses (R) plus the sum of 
Table 1. Characteristics of the study population $(\mathrm{N}=315)$.

\begin{tabular}{|c|c|}
\hline Variable & $\mathrm{M}(\mathrm{SD})$ \\
\hline \multicolumn{2}{|l|}{ Demographic variables } \\
\hline Men $(\%)$ & 24.4 \\
\hline Age (years) & $32.8(6.8)$ \\
\hline Married (\%) & 49.2 \\
\hline University degree (\%) & 25.4 \\
\hline \multicolumn{2}{|l|}{ Diagnoses } \\
\hline Mood disorder only (\%) & 55.2 \\
\hline Anxiety disorder only (\%) & 15.9 \\
\hline Co-morbid mood and anxiety disorder (\%) & 28.9 \\
\hline Personality disorder (\%) & 18.4 \\
\hline \multicolumn{2}{|l|}{ Psychiatric symptoms } \\
\hline Symptom checklist, global severity index (SCL-90-GSI) & $1.28(0.5)$ \\
\hline Beck depression inventory (BDI) & $18.2(7.8)$ \\
\hline Symptom checklist, anxiety scale (SCL-90-Anx) & $1.24(0.6)$ \\
\hline \multicolumn{2}{|l|}{ Psychiatric history } \\
\hline Previous psychotherapy (\%) & 18.6 \\
\hline Previous medication (\%) & 22.0 \\
\hline \multicolumn{2}{|l|}{ Personality functions } \\
\hline Suitability for psychotherapy scale (SPS) & $2.36(1.70)$ \\
\hline Inventory of interpersonal problems (IIP) & $86.9(31.0)$ \\
\hline Quality of object relations scale (QORS) & $5.13(0.60)$ \\
\hline Quality of object relations scale (QORS) > 5 (\%) & 58.7 \\
\hline
\end{tabular}

six weighted subcomponents relating to ego functions: perceptual inaccuracy and poor reality testing (FQ-), impaired reasoning and disorganized thought (WSum6), the expression of disturbed contents that are typically censored in adaptive thinking (Critical Contents; anatomy, blood, fire, explosions, sex, X-ray, aggressive movement, and morbid content responses), thought disturbance capturing distortions in object representations (M-), and adaptive versus problematic representations of people and interactions (Good (GHR) and Poor (PHR) Human Representation Variables (HRV)) [28]. Summary scores from protocols were calculated with the RIAP-3 program. The EII-2 score and its subcomponents GHR and PHR were derived from the summary scores via the Rorschach Research Utilities (RRU) program [29] and SPSS software.

\subsubsection{The Quality of Object Relations Scale (QORS)}

The Quality of Object Relations Scale (QORS) [14] is an interview-based assessment scale based on psychoanalytic object relation theory and designed to quan- 
tify the overall quality of object relations. The assessment consists of five items with object relational levels ranging from low to high: primitive, searching, controlling, triangular, and mature. A total of 100 points were distributed between these five levels according to their relative representation (percentage) among the patient's patterns of object relations. The original ratings were multiplied by the weight according to the level of the object relational pattern, i.e., from primitive to mature, $1,3,5,7$, and 9 , and the values were then summed and divided by 100. Thus, the QORS score ranged from 1 to 9. The QORS scores were dichotomized using a cut-off point of 5.0 to form a low $(\leq 5)$ and high QORS $(>5)$ group. The reliability and concurrent validity of the dichotomized QORS have reportedly been adequate [27].

\subsubsection{The Suitability for Psychotherapy Scale (SPS)}

The interview-based Suitability for Psychotherapy Scale (SPS) [1] was developed in the Helsinki Psychotherapy Study to measure psychological suitability for psychotherapy. The assessment of ego strength is a central focus in the 7-item SPS, including three items on affect modulation, flexibility of social interaction, and the relationship between the current self-concept and ego ideal. Other dimensions of the SPS score include three items related to self-observing capacity and one related to the nature of problems (specific vs. unspecific). The total SPS score was formed by summing the seven dichotomized suitability items ( $\operatorname{good}=0$, poor $=1$ ) so that the score ranges from 0 to 7 . The score was further categorized into three groups: low (0 - 3), intermediate (4 - 6), and high (7), where a low score designates good suitability and intermediate and high values poor suitability for psychotherapy. The SPS has shown fair to good reliability, good criterion and discrimination validity, and a good predictive ability with regard to the outcome of short-term and long-term psychotherapy [1] [16] [17].

\subsubsection{The Inventory of Interpersonal Problems (IIP)}

The Inventory of Interpersonal Problems (IIP-64) [15] is a 64-item self-report measure providing information on interpersonal problems and distress in two sections: "The following are things that you find hard to do with other people" and "The following are things that you do too much". The response options are scored on a 5-point scale ranging from 0 (not at all) to 4 (extremely). The total IIP score, i.e. the overall severity of the person's current interpersonal problems, was obtained by summing all 64 scores of both sections.

\subsubsection{Other Methods}

Psychiatric diagnoses were assessed by semi-structured interview [23] and based on DSM-IV diagnostic criteria [30]. Both clinical disorders (axis I) and personality disorders (axis II) were diagnosed. General psychiatric symptoms were assessed with the Symptom Check List, Global Severity Index (SCL-90-GSI) [31], anxiety symptoms with the Symptom Check List, Anxiety Scale (SCL-90-Anx) [31], depressive symptoms using the Beck Depression Inventory (BDI) [32], and psychosocial functioning with the Global Assessment of Functioning scale (GAF) [30]. So- 
cioeconomic factors (sex, age, marital status, and education) and psychiatric history (previous psychotherapy and previous medication) were assessed with questionnaires and interviews.

\subsubsection{Statistical Methods}

In this cross-sectional study, the strength of the association between the Rorschach variables and the other variables of interest was estimated using linear regression analysis model [33]. The EII-2 and its subcomponents were included in basic models as dependent variables and the QORS, SPS, and IIP in separate models as independent variables. Variables satisfying the criteria for a confounding factor [34], SCL-90-GSI, SCL-90-Anx, GAF, BDI (all included as continuous variables), and the onset of the primary psychiatric disorder (included as a categorical variable) were further included in a complete model. The three continuous independent variables of interest (QORS, SPS, and IIP) were included as continuous variables in their original form and also categorized (QORS as dichotomous, SPS in three categories, and IIP categorized by quartiles) in parallel models to avoid potential biases resulting from the linearity assumption inherent in the use of continuous variables [35].

Model-adjusted mean levels of the dependent variables were estimated from the regression coefficients in the categories of the independent variables of interest using predictive means [36]. For the continuous variables, partial correlation coefficients estimated based on the model were presented.

The significance of the associations between the independent and dependent variables was computed using the F-test. A test for trend was performed in the case of continuous independent variables, and a test for heterogeneity in the case of categorical variables. The statistical analyses were carried out using the package SAS, version 9 [37].

\section{Results}

The overall EII-2 index was not associated with the SPS. There was one statistically significant association between the EII-2 subcomponents and the SPS in the total study group $(\mathrm{N}=315)$ (Table 2$)$. Patients with the lowest, and thus the best, values for the SPS demonstrated the highest values for good human representational responses (GHR), indicating social interpersonal behaviors more adaptive to the situation with the continuous SPS value $(r=0.17, \mathrm{p}$-value for trend $=$ 0.003). A similar association between the SPS and the GHR was observed in patients without personality disorder $(\mathrm{r}=0.20, \mathrm{p}$-value for trend $=0.002)$. Adjustments for psychiatric symptoms and psychiatric history did not alter these findings. In addition, a statistically significant difference was detected in the number of given Rorschach responses between the three SPS categories in the personality disorder group $(r=0.35$, $p$-value for heterogeneity $=0.03$ ) (data not shown). However, this association did not remain significant in the model adjusted for confounding factors.

The EII- 2 total score was associated with the IIP $(r=0.15, p$-value for trend 
Table 2. Association of the Rorschach ego impairment index (EII-2) and its subcomponents and the suitability for psychotherapy (SPS): mean (SD) values of the EII-2 variables by category of SPS and correlation of the EII-2 variables with the continuous SPS index.

\begin{tabular}{|c|c|c|c|c|c|c|c|c|c|c|}
\hline \multicolumn{5}{|c|}{$\begin{array}{l}\text { Unadjusted mean values and standard deviations of } \\
\text { EII- } 2 \text { by SPS category }\end{array}$} & \multirow{2}{*}{$\begin{array}{c}\mathrm{p} \text {-value for } \\
\text { trend }^{2}\end{array}$} & \multicolumn{4}{|c|}{$\begin{array}{l}\text { Model-adjusted }{ }^{1} \text { mean values of } \\
\text { EII- } 2 \text { by SPS category }\end{array}$} & \multirow{2}{*}{$\begin{array}{l}\text { p-value for } \\
\text { trend }^{2}\end{array}$} \\
\hline $\begin{array}{c}\text { EII-2 } \\
\text { variables }\end{array}$ & $\begin{array}{c}1^{\text {st }} \text { category } \\
0-1\end{array}$ & $\begin{array}{c}2^{\text {nd }} \text { category } \\
2-5\end{array}$ & $\begin{array}{c}3^{\text {rd }} \text { category } \\
6-7\end{array}$ & $\begin{array}{c}\text { Correlation } \\
\text { coefficient }\end{array}$ & & $\begin{array}{c}1^{\text {st }} \text { category } \\
0-1\end{array}$ & $\begin{array}{c}2^{\text {nd }} \text { category } \\
2-5\end{array}$ & $\begin{array}{c}3^{\text {rd }} \text { category } \\
6-7\end{array}$ & $\begin{array}{l}\text { Correlation } \\
\text { coefficient }\end{array}$ & \\
\hline \multicolumn{11}{|c|}{ All patients $(\mathrm{N}=315)$} \\
\hline $\mathrm{N}$ & 247 & 61 & 7 & & & 247 & 61 & 7 & & \\
\hline EII-2 & $0.02(1.08)$ & $0.44(1.74)$ & $0.06(1.14)$ & 0.09 & 0.12 & 0.03 & 0.43 & 0.16 & 0.09 & 0.14 \\
\hline $\mathrm{R}$ & $26.2(10.1)$ & $25.5(9.2)$ & $24.3(9.56)$ & 0.04 & 0.43 & 26.2 & 25.5 & 24.5 & 0.05 & 0.41 \\
\hline Critical C & $6.66(4.38)$ & $6.80(4.63)$ & $5.53(3.69)$ & 0.05 & 0.37 & 6.68 & 6.76 & 5.82 & 0.05 & 0.36 \\
\hline GHR & $5.31(2.51)$ & $4.97(2.46)$ & $4.11(2.03)$ & 0.17 & 0.003 & 5.34 & 4.97 & 4.00 & 0.18 & 0.001 \\
\hline PHR & $3.75(2.64)$ & $4.54(3.76)$ & $3.56(3.40)$ & 0.05 & 0.43 & 3.76 & 4.53 & 3.64 & 0.04 & 0.52 \\
\hline M- & $1.09(1.20)$ & $1.41(1.61)$ & $0.89(1.29)$ & 0.02 & 0.70 & 1.09 & 1.40 & 1.01 & 0.03 & 0.58 \\
\hline FQ- & $4.37(2.89)$ & $4.54(3.52)$ & $4.10(3.70)$ & 0.02 & 0.77 & 4.36 & 4.53 & 4.23 & 0.007 & 0.91 \\
\hline WSum6 & $11.9(11.1)$ & $14.7(15.1)$ & $10.5(9.88)$ & 0.03 & 0.54 & 12.0 & 14.6 & 11.0 & 0.02 & 0.66 \\
\hline \multicolumn{11}{|c|}{ Patients with personality disorder ${ }^{3}(\mathrm{~N}=58)$} \\
\hline $\mathrm{N}$ & 34 & 21 & 3 & & & 34 & 21 & 3 & & \\
\hline EII-2 & $0.09(1.24)$ & $0.94(2.29)$ & $0.57(1.42)$ & 0.009 & 0.95 & 0.32 & 0.88 & 0.62 & 0.06 & 0.68 \\
\hline $\mathrm{R}$ & $27.8(11.9)$ & $22.4(6.90)$ & $38.3(11.6)$ & 0.04 & 0.77 & 28.1 & 22.2 & 35.6 & 0.10 & 0.52 \\
\hline Critical C & $9.24(6.37)$ & $6.85(3.33)$ & $9.00(2.65)$ & 0.14 & 0.29 & 9.46 & 6.68 & 7.74 & 0.22 & 0.14 \\
\hline GHR & $5.09(2.33)$ & $4.50(1.82)$ & $5.67(2.89)$ & 0.05 & 0.73 & 5.09 & 4.54 & 5.51 & 0.07 & 0.65 \\
\hline PHR & $5.19(4.34)$ & $3.65(3.00)$ & $8.00(6.08)$ & 0.04 & 0.80 & 5.40 & 3.61 & 6.01 & 0.05 & 0.72 \\
\hline M- & $1.42(1.80)$ & $1.10(1.65)$ & $2.00(2.65)$ & 0.02 & 0.86 & 1.41 & 1.21 & 1.45 & 0.01 & 0.94 \\
\hline FQ- & $4.76(3.90)$ & $3.80(2.63)$ & $8.67(6.66)$ & 0.03 & 0.84 & 5.01 & 3.76 & 6.13 & 0.12 & 0.43 \\
\hline WSum6 & $20.3(22.8)$ & $19.0(16.6)$ & $14.3(9.07)$ & 0.03 & 0.83 & 20.2 & 19.9 & 8.93 & 0.04 & 0.77 \\
\hline \multicolumn{11}{|c|}{ Patients without personality disorder $(\mathrm{N}=257)$} \\
\hline $\mathrm{N}$ & 213 & 40 & 4 & & & 213 & 40 & 4 & & \\
\hline EII-2 & $0.01(1.07)$ & $0.30(1.54)$ & $-0.24(0.86)$ & 0.08 & 0.23 & 0.0008 & 0.30 & -0.10 & 0.09 & 0.17 \\
\hline $\mathrm{R}$ & $25.5(9.06)$ & $26.0(10.5)$ & $19.8(4.43)$ & 0.06 & 0.33 & 25.4 & 26.3 & 19.5 & 0.06 & 0.39 \\
\hline Critical C & $6.42(4.06)$ & $5.87(4.96)$ & $4.25(2.50)$ & 0.09 & 0.15 & 6.40 & 5.97 & 4.35 & 0.08 & 0.20 \\
\hline GHR & $5.20(2.54)$ & $4.58(2.36)$ & $3.00(2.16)$ & 0.20 & 0.002 & 5.19 & 4.64 & 2.86 & 0.20 & 0.001 \\
\hline PHR & $4.05(2.89)$ & $4.47(4.80)$ & $2.00(2.45)$ & 0.02 & 0.73 & 4.04 & 4.53 & 1.95 & 0.03 & 0.67 \\
\hline M- & $1.26(1.34)$ & $1.33(1.69)$ & $0.50(1.00)$ & 0.01 & 0.82 & 1.24 & 1.41 & 0.48 & 0.03 & 0.59 \\
\hline FQ- & $4.35(2.88)$ & $4.97(4.72)$ & $2.50(2.38)$ & 0.006 & 0.93 & 4.34 & 5.06 & 2.40 & 0.02 & 0.76 \\
\hline WSum6 & $12.4(11.4)$ & $11.3(10.9)$ & $3.25(2.87)$ & 0.02 & 0.75 & 12.5 & 11.0 & 2.86 & 0.02 & 0.76 \\
\hline
\end{tabular}

Note. $\mathrm{BDI}=$ Beck Depression Inventory; Critical C = Critical Contents; EII-2 = Ego Impairment Index; FQ- = Distorted perceptions; GAF = Global Assessment of Functioning scale; GHR = Good Human Representations; M- = Distorted object representations; PHR = Poor Human Representations; R = Number of Responses; SCL-90-Anx = Symptom Checklist, Anxiety Scale; SCL-90-GSI = Symptom Checklist, Global Severity Index; WSum6 = Disorganized thought. ${ }^{1}$ Model: The mean Rorschach values in the three SPS categories were adjusted for SCL-90-GSI, SCL-90-Anx, GAF, BDI (all included as continuous variables), and onset of primary psychiatric disorder (included as a categorical variable). ${ }^{2}$ Test for trend between the Rorschach variables and the continuous SPS index. ${ }^{3}$ Patients with diagnoses on Axis II (personality disorder). ${ }^{4}$ Missing values in variables in the analyses ranging from 0 - 11. 
$=0.007$ ), indicating the highest level of psychological impairment among patients with the highest values for self-reported interpersonal problems (Table 3). The association was found to be even stronger in the personality disorder group $(r=0.27$, $\mathrm{p}$-value for trend $=0.04$ ), whereas no significant association was found in patients belonging to the non-personality disorder group. Patients with more self-reported interpersonal problems scored significantly higher on the EII-2 subcomponent, demonstrating failure to defend against primitive impulses (Critical Contents), with respect to the continuous IIP score $(r=0.12$, $\mathrm{p}$-value for trend $=0.03$ ). WSum6 was found to be significantly associated with the continuous IIP, indicating a higher level of thought disturbances among patients with more self-reported interpersonal problems $(\mathrm{r}=0.14, \mathrm{p}$-value for trend $=0.02)$. In addition, the results showed a statistically significant correlation between the PHR and the continuous IIP among patients with personality disorder $(\mathrm{r}=0.32$, $\mathrm{p}$-value for trend $=0.02)$. However, all of the significant associations between the EII-2 scores (total EII-2, Critical Contents, WSum6 and PHR) and the continuous IIP score disappeared after adjustment for confounding factors (Table 3). A statistically significant difference appeared, however, in the mean scores between PHR and the IIP quartiles in the personality disorder group, indicating more flawed representations of interactions among patients with greater self-reported interpersonal distress $(r=0.42, p$-value for heterogeneity $=0.04)($ data not shown $)$.

Lower values of the QORS were significantly associated with more ego impairment in the EII-2 $(r=0.13$, p-value for trend $=0.02$, Table 4$)$ in the total study group, as well as in the non-personality disorder group $(r=0.13$, $\mathrm{p}$-value for trend $=0.04$ ). After adjustment for psychiatric symptoms and history, the association between the continuous QORS and the EII-2 did not reach significance. However, the analysis of the categorized QORS indicated that patients with a low QORS displayed more ego impairment in the EII-2 than patients with a high QORS among those without personality disorder $(r=0.14$, $\mathrm{p}$-value for heterogeneity $=0.03$ ) (results not shown). The significant association between the WSum6 and the QORS scores $(\mathrm{r}=0.15$, $\mathrm{p}$-value for trend $=0.007)$ indicated that patients with lower QORS values showed the greatest levels of arbitrary thinking in the total study group. The findings were mainly similar among patients in the non-personality disorder group, and the associations were slightly attenuated after adjustment. In the personality disorder group, the association between $M$ - and the continuous QORS became significant after adjustment $(r=0.33$, p-value for trend $=0.02$ ), indicating more distortions in interpersonal perceptions among patients with a higher QORS.

\section{Discussion}

\subsection{General Findings}

To the best of our knowledge, this is the first study investigating associations between the Rorschach EII-2 and the SPS, IIP, and QORS. Most of the detected 
Table 3. Association of the Rorschach ego impairment index (EII-2) and its subcomponents and the inventory of interpersonal problems (IIP): mean (SD) values of the EII-2 variables in four categories of IIP and correlation of the EII-2 variables with the continuous IIP index.

\begin{tabular}{|c|c|c|c|c|c|c|c|c|c|c|c|c|}
\hline & Unadjusted & $\begin{array}{l}\text { mean values } \\
\text { of EII- } 2 \text { by I }\end{array}$ & $\begin{array}{l}\text { and standard } \\
\text { IP quartile }\end{array}$ & deviations & & & & $\begin{array}{r}\text { Model-a } \\
\text { of EI }\end{array}$ & $\begin{array}{l}\text { adjusted }^{1}{ }^{1} \\
\text { II-2 by IIP }\end{array}$ & $\begin{array}{l}\text { mean value } \\
\text { quartile }\end{array}$ & & value \\
\hline $\begin{array}{c}\text { EII } \\
\text { variables }^{4}\end{array}$ & $\begin{array}{c}1^{\text {st }} \text { quartile } \\
12-66\end{array}$ & $\begin{array}{c}2^{\text {nd }} \text { quartile } \\
67-88\end{array}$ & $\begin{array}{c}3^{\text {rd }} \text { quartile } \\
89-106\end{array}$ & $\begin{array}{c}4^{\text {th }} \text { quartile } \\
108-162\end{array}$ & $\begin{array}{c}\text { Correlation } \\
\text { coefficient }\end{array}$ & $\begin{array}{l}\text { for } \\
\text { trend }^{2}\end{array}$ & $\begin{array}{c}1^{\text {st }} \\
\text { quartile } \\
12-66\end{array}$ & $\begin{array}{c}2^{\text {nd }} \\
\text { quartile } \\
67-88\end{array}$ & $\begin{array}{c}3^{\text {rd }} \\
\text { quartile } \\
89-106\end{array}$ & $\begin{array}{c}4^{\text {th }} \\
\text { quartile } \\
108-162\end{array}$ & $\begin{array}{l}\text { Correlation } \\
\text { coefficient }\end{array}$ & $\begin{array}{c}\text { for } \\
\text { trend }^{2}\end{array}$ \\
\hline All patier & nts $(\mathrm{N}=315)$ & & & & & & & & & & & \\
\hline $\mathrm{N}$ & 78 & 77 & 76 & 79 & & & 78 & 77 & 76 & 79 & & \\
\hline EII-2 & $-0.02(1.63)$ & $0.15(1.14)$ & $0.33(1.67)$ & $0.59(1.56)$ & 0.15 & 0.007 & 0.09 & 0.18 & 0.31 & 0.48 & 0.07 & 0.20 \\
\hline $\mathrm{R}$ & $25.9(10.0)$ & $24.5(9.04)$ & $25.8(8.21)$ & $26.0(10.5)$ & 0.004 & 0.95 & 25.8 & 24.5 & 25.9 & 26.1 & 0.001 & 0.98 \\
\hline Critical C & $6.17(4.51)$ & $6.17(3.99)$ & $7.13(4.66)$ & $7.20(4.78)$ & 0.12 & 0.03 & 6.16 & 6.16 & 7.17 & 7.19 & 0.10 & 0.08 \\
\hline GHR & $5.41(2.66)$ & $4.73(2.27)$ & $5.31(2.35)$ & $4.66(2.53)$ & 0.09 & 0.11 & 5.38 & 4.77 & 5.27 & 4.70 & 0.07 & 0.21 \\
\hline PHR & $3.81(3.76)$ & $3.74(2.82)$ & $4.30(3.00)$ & $4.79(3.74)$ & 0.10 & 0.09 & 3.99 & 3.77 & 4.28 & 4.62 & 0.04 & 0.54 \\
\hline M- & $1.14(1.48)$ & $1.16(1.14)$ & $1.43(1.63)$ & $1.29(1.54)$ & 0.05 & 0.38 & 1.24 & 1.19 & 1.41 & 1.19 & 0.02 & 0.75 \\
\hline FQ- & $4.08(3.38)$ & $4.22(3.04)$ & $4.50(3.06)$ & $4.86(3.62)$ & 0.07 & 0.21 & 4.36 & 4.27 & 4.45 & 4.58 & 0.009 & 0.88 \\
\hline WSum6 & $11.0(10.7)$ & $12.2(11.3)$ & $14.3(16.4)$ & $16.1(14.8)$ & 0.14 & 0.02 & 11.3 & 12.4 & 14.2 & 15.7 & 0.09 & 0.12 \\
\hline Patients & with personali & ty disorder ${ }^{3}($ & $N=56)$ & & & & & & & & & \\
\hline $\mathrm{N}$ & 10 & 13 & 18 & 15 & & & 10 & 10 & 18 & 15 & & \\
\hline EII-2 & $0.12(1.69)$ & $\begin{array}{l}-0.27 \\
(0.54)\end{array}$ & $1.04(2.56)$ & $1.69(2.04)$ & 0.27 & 0.04 & 0.45 & -0.38 & 0.97 & 1.64 & 0.20 & 0.17 \\
\hline $\mathrm{R}$ & $27.8(13.8)$ & $22.9(11.2)$ & $27.3(11.0)$ & $27.4(8.81)$ & 0.009 & 0.95 & 30.9 & 21.5 & 27.4 & 26.4 & 0.07 & 0.63 \\
\hline Critical C & $8.60(5.68)$ & $6.38(3.45)$ & $8.22(6.15)$ & $10.1(5.49)$ & 0.12 & 0.40 & 8.99 & 6.06 & 7.71 & 10.8 & 0.15 & 0.31 \\
\hline GHR & $5.60(2.59)$ & $4.85(2.23)$ & $4.94(1.98)$ & $4.43(2.14)$ & 0.15 & 0.26 & 6.25 & 4.78 & 4.82 & 4.19 & 0.23 & 0.13 \\
\hline PHR & $3.30(2.67)$ & $2.62(1.76)$ & $5.22(4.35)$ & $7.29(4.76)$ & 0.32 & 0.02 & 4.57 & 2.18 & 5.19 & 6.88 & 0.22 & 0.14 \\
\hline M- & $1.10(1.37)$ & $0.38(0.65)$ & $1.67(2.17)$ & $1.93(1.91)$ & 0.17 & 0.20 & 1.53 & 0.32 & 1.56 & 1.82 & 0.07 & 0.66 \\
\hline FQ- & $4.30(4.62)$ & $3.23(1.96)$ & $4.83(4.22)$ & $5.80(3.59)$ & 0.08 & 0.53 & 6.14 & 2.74 & 4.64 & 5.23 & 0.06 & 0.68 \\
\hline WSum6 & $15.8(14.2)$ & $10.5(8.52)$ & $24.2(26.6)$ & $24.3(19.7)$ & 0.17 & 0.21 & 17.4 & 9.14 & 24.6 & 23.8 & 0.12 & 0.41 \\
\hline Patients $\mathrm{w}$ & vithout person & ality disorder & $(\mathrm{N}=254)$ & & & & & & & & & \\
\hline $\mathrm{N}$ & 68 & 64 & 58 & 64 & & & 68 & 64 & 58 & 64 & & \\
\hline EII-2 & $-0.04(1.64)$ & $0.24(1.21)$ & $0.11(1.22)$ & $0.33(1.32)$ & 0.11 & 0.08 & -0.04 & 0.26 & 0.12 & 0.23 & 0.04 & 0.56 \\
\hline $\mathrm{R}$ & $25.6(9.45)$ & $24.8(8.62)$ & $25.4(7.21)$ & $25.7(10.9)$ & 0.004 & 0.95 & 25.1 & 24.8 & 25.5 & 26.1 & 0.03 & 0.65 \\
\hline Critical C & $5.81(4.25)$ & $6.13(4.12)$ & $6.79(4.10)$ & $6.52(4.37)$ & 0.11 & 0.07 & 5.87 & 6.09 & 6.86 & 6.42 & 0.09 & 0.18 \\
\hline GHR & $5.38(2.68)$ & $4.70(2.30)$ & $5.43(2.46)$ & $4.71(2.62)$ & 0.08 & 0.21 & 5.26 & 4.78 & 5.36 & 4.84 & 0.04 & 0.51 \\
\hline PHR & $3.89(3.91)$ & $3.98(2.96)$ & $4.02(2.42)$ & $4.24(3.27)$ & 0.04 & 0.57 & 3.91 & 4.01 & 4.03 & 4.18 & 0.01 & 0.90 \\
\hline M- & $1.15(1.50)$ & $1.32(1.16)$ & $1.36(1.44)$ & $1.14(1.41)$ & 0.01 & 0.82 & 1.22 & 1.36 & 1.35 & 1.04 & 0.04 & 0.51 \\
\hline FQ- & $4.04(3.20)$ & $4.43(3.20)$ & $4.40(2.64)$ & $4.64(3.62)$ & 0.07 & 0.29 & 4.16 & 4.46 & 4.42 & 4.48 & 0.02 & 0.77 \\
\hline WSum6 & $10.3(10.0)$ & $12.5(11.8)$ & $11.3(10.1)$ & $14.2(12.9)$ & 0.12 & 0.06 & 10.2 & 12.7 & 11.3 & 14.0 & 0.08 & 0.19 \\
\hline
\end{tabular}

Note BDI = Beck Depression Inventory; Critical C = Critical Contents; EII-2 = Ego Impairment Index; FQ- = Distorted perceptions; GAF = Global Assessment of Functioning scale; GHR = Good Human Representations; M- = Distorted object representations; PHR = Poor Human Representations; R = Number of Responses; SCL-90-Anx = Symptom Checklist, Anxiety Scale; SCL-90-GSI = Symptom Checklist, Global Severity Index; WSum6 = Disorganized thought. ${ }^{1}$ Model: The mean Rorschach values in the four IIP quartiles were adjusted for SCL-90-GSI, SCL-90-Anx, GAF, BDI (all included as continuous variables), and onset of primary psychiatric disorder (included as a categorical variable). ${ }^{2}$ Test for trend between the Rorschach variables and the continuous IIP index. ${ }^{3}$ Patients with diagnoses on Axis II (personality disorder). ${ }^{4}$ Missing values in variables in the analyses ranging from 0 - 13. 
Table 4. Association of the Rorschach ego impairment index (EII-2) and its subcomponents and the quality of object relations scale (QORS): mean (SD) values of the EII-2 variables in two categories of QORS and correlation of EII-2 variables with the continuous QORS index.

\begin{tabular}{|c|c|c|c|c|c|c|c|c|}
\hline \multicolumn{4}{|c|}{$\begin{array}{l}\text { Unadjusted mean values and standard deviations } \\
\text { of EII-2 by QORS category }\end{array}$} & \multirow{2}{*}{$\begin{array}{l}\mathrm{p} \text {-value for } \\
\text { trend }^{2}\end{array}$} & \multicolumn{3}{|c|}{$\begin{array}{l}\text { Model-adjusted mean values } \\
\text { of EII-2 by QORS category }\end{array}$} & \multirow{2}{*}{$\begin{array}{l}\text { p-value for } \\
\text { trend }^{2}\end{array}$} \\
\hline $\begin{array}{c}\text { EII } \\
\text { variables }^{4}\end{array}$ & $0-5$ & $>5$ & $\begin{array}{c}\text { Correlation } \\
\text { coefficient }\end{array}$ & & $0-5$ & $>5$ & $\begin{array}{l}\text { Correlation } \\
\text { coefficient }\end{array}$ & \\
\hline \multicolumn{9}{|c|}{ All patients $(\mathrm{N}=315)$} \\
\hline $\mathrm{N}$ & 130 & 185 & & & 130 & 185 & & \\
\hline EII-2 & $0.54(1.78)$ & $0.08(1.29)$ & 0.13 & 0.02 & 0.48 & 0.13 & 0.07 & 0.22 \\
\hline $\mathrm{R}$ & $24.9(10.2)$ & $26.2(9.05)$ & 0.01 & 0.87 & 24.7 & 26.3 & 0.02 & 0.72 \\
\hline Critical C & $7.02(4.92)$ & $6.43(4.17)$ & 0.03 & 0.62 & 6.84 & 6.56 & 0.01 & 0.81 \\
\hline GHR & $4.83(2.52)$ & $5.18(2.42)$ & 0.01 & 0.81 & 4.84 & 5.18 & 0.03 & 0.58 \\
\hline PHR & $4.39(3.91)$ & $4.09(3.02)$ & 0.08 & 0.15 & 4.26 & 4.17 & 0.05 & 0.44 \\
\hline M- & $1.29(1.62)$ & $1.26(1.35)$ & 0.04 & 0.51 & 1.23 & 1.30 & 0.004 & 0.95 \\
\hline FQ- & $4.47(3.48)$ & $4.44(3.22)$ & 0.04 & 0.49 & 4.23 & 4.55 & 0.01 & 0.86 \\
\hline WSum6 & $16.0(15.1)$ & $11.7(12.1)$ & 0.15 & 0.007 & 15.6 & 12.0 & 0.11 & 0.05 \\
\hline \multicolumn{9}{|c|}{ Patients with personality disorder ${ }^{3}(\mathrm{~N}=58)$} \\
\hline $\mathrm{N}$ & 40 & 18 & & & 40 & 18 & & \\
\hline EII-2 & $0.74(2.16)$ & $0.76(1.84)$ & 0.05 & 0.70 & 0.58 & 1.12 & 0.17 & 0.24 \\
\hline $\mathrm{R}$ & $25.8(10.9)$ & $27.9(11.1)$ & 0.10 & 0.48 & 24.9 & 29.8 & 0.18 & 0.22 \\
\hline Critical C & $8.46(5.67)$ & $8.18(4.85)$ & 0.08 & 0.54 & 8.23 & 8.71 & 0.17 & 0.26 \\
\hline GHR & $5.18(2.18)$ & $4.29(2.08)$ & 0.18 & 0.19 & 5.19 & 4.27 & 0.13 & 0.37 \\
\hline PHR & $4.79(4.36)$ & $4.76(3.44)$ & 0.07 & 0.59 & 4.29 & 5.88 & 0.26 & 0.08 \\
\hline M- & $1.18(1.76)$ & $1.71(1.79)$ & 0.13 & 0.33 & 0.91 & 2.33 & 0.33 & 0.02 \\
\hline FQ- & $4.51(3.72)$ & $4.88(3.89)$ & 0.01 & 0.93 & 4.06 & 5.92 & 0.17 & 0.24 \\
\hline WSum6 & $19.5(21.2)$ & $19.7(17.8)$ & 0.06 & 0.65 & 18.7 & 21.5 & 0.13 & 0.37 \\
\hline \multicolumn{9}{|c|}{ Patients without personality disorder $(\mathrm{N}=257)$} \\
\hline $\mathrm{N}$ & 90 & 167 & & & 90 & 167 & & \\
\hline EII-2 & $0.47(1.59)$ & $0.01(1.20)$ & 0.13 & 0.04 & 0.43 & 0.03 & 0.10 & 0.13 \\
\hline $\mathrm{R}$ & $24.6(9.95)$ & $26.0(8.84)$ & 0.007 & 0.91 & 24.5 & 26.0 & 0.002 & 0.98 \\
\hline Critical C & $6.39(4.43)$ & $6.25(4.07)$ & 0.03 & 0.61 & 6.27 & 6.31 & 0.05 & 0.41 \\
\hline GHR & $4.67(2.65)$ & $5.28(2.44)$ & 0.004 & 0.95 & 4.71 & 5.26 & 0.02 & 0.74 \\
\hline PHR & $4.21(3.71)$ & $4.02(2.98)$ & 0.09 & 0.14 & 4.18 & 4.04 & 0.09 & 0.17 \\
\hline M- & $1.34(1.57)$ & $1.21(1.30)$ & 0.08 & 0.21 & 1.32 & 1.22 & 0.07 & 0.28 \\
\hline FQ- & $4.45(3.39)$ & $4.40(3.15)$ & 0.04 & 0.49 & 4.44 & 4.41 & 0.03 & 0.61 \\
\hline WSum6 & $14.5(11.2)$ & $10.9(11.2)$ & 0.14 & 0.02 & 14.2 & 11.0 & 0.11 & 0.07 \\
\hline
\end{tabular}

Note. BDI = Beck Depression Inventory; Critical C = Critical Contents; EII-2 = Ego Impairment Index; FQ- = Distorted perceptions; GAF = Global Assessment of Functioning scale; GHR = Good Human Representations; M- = Distorted object representations; PHR = Poor Human Representations; R = Number of Responses; SCL-90-Anx = Symptom Checklist, Anxiety Scale; SCL-90-GSI = Symptom Checklist, Global Severity Index; WSum6 = Disorganized thought. ${ }^{1}$ Model: The mean Rorschach values in the four IIP quartiles were adjusted for SCL-90-GSI, SCL-90-Anx, GAF, BDI (all included as continuous variables), and onset of primary psychiatric disorder (included as a categorical variable). ${ }^{2}$ Test for trend between the Rorschach variables and the continuous QORS index. ${ }^{3}$ Patients with diagnoses on Axis II (personality disorder). ${ }^{4}$ Missing values in variables in the analyses ranging from 2 - 11. 
associations between the EII-2 and the other assessment measures were weak to modest, but mostly in the hypothesized direction.

In models adjusted for psychiatric symptoms and the onset of the primary psychiatric disorder, no associations in the total sample were detected between the EII-2 total score and SPS, IIP, or QORS. Nevertheless, the EII-2 subcomponent GHR was weakly associated with the SPS, even when adjusted for psychiatric symptoms and history. This result indicates that there is a consistent association between interview-based assessment of the psychological suitability for psychotherapy and the measurement of situationally adaptive interpersonal behaviors, based on the GHR. The SPS has been shown to be rather independent of psychiatric symptoms [1]. Thus, the finding that the association between the SPS and the GHR remained unaltered in adjusted models was understandable and emphasizes the potential utility of both the SPS and the GHR in measuring the underlying psychological capacity beyond the symptom level.

Both the SPS and Rorschach are based on clinical evaluation of an individual's behavior, and possibly enable tapping of the underlying developmental disruption beyond the assessment of symptoms. Good values in the SPS indicate the ability to process problems within a psychotherapeutic relationship, thus reflecting a specific intrapsychic and interpersonal functional capacity. The GHR score, like the PHR, was developed to summarize the interpersonal perception information available from the Rorschach [28]. The GHR is interpreted to indicate accurately perceived, intact mental representations of people and interactions. Theoretically, individuals with good values in the GHR are more likely to be interpersonally effective and capable of positive involvement and relatedness; their behavior in social situations is more likely to be influenced by adequate understanding of others and their intentions, and less likely to be influenced by their own wishes, fears, and fantasies. This detected association between the SPS and the GHR may reflect that although the GHR is an indicator of the nonobservable underlying structure, indicating adaptive understanding of others, it seems to measure some aspect of this interaction, which is salient to the interviewers in the SPS. It is possible that the GHR taps a partly different set of interpersonal capacities compared to the SPS. Our finding that the GHR was associated with the SPS suggests that the GHR, like the SPS, might have potential utility in predicting the outcome of psychotherapy [6]. Thus, the prediction of the GHR, in comparison to the SPS, should be addressed in future studies.

Our findings concerning the models without adjustment for psychiatric symptoms and the onset of the primary psychiatric disorder further showed that in the total sample, both the EII-2 and its subcomponent, WSum6, were statistically significantly associated with both interpersonal problems measured by the IIP and the quality of object relations measured by the QORS, as hypothesized. Thus, both current interpersonal problems and immature lifelong relational patterns, irrespective whether assessed by self-report of interview, were associated with thought disturbances and the level of psychological impairment measured by these 
Rorschach measures. Regarding the EII-2, high scores reflecting psychological impairment may result in problematic interpersonal behavior, leading to negative interactions with other people. Likewise, disorganized thought and language, indicated by a high value for WSum6, may preclude social relationships, e.g., by leading to a lack of judgment and insight impairment [38], as well as leading to misinterpretation of the behavior of others. This is in accordance with a previous finding based on data from the Helsinki Psychotherapy Study [13] demonstrating an association between WSum6 and the Level of Personality Organization (LPO) scale. In that study, however, the associations of the EII-2 and WSum6 with the LPO appeared to be somewhat stronger than the associations of the EII-2 and WSum6 with the IIP and QORS in our study. Furthermore, in the previous study, the findings remained mainly similar in the adjusted models. On the other hand, Nygren [39] found no correlation between WSum6 and clinical ratings of Dynamic Capacity or Ego Strength. In addition, failure to defend against primitive impulses (Critical Contents) was associated with more self-reported interpersonal distress in the IIP. This could be interpreted as indicting that failure to repress images usually inhibited in social discourse may be related to, and perhaps predispose to, interpersonal problems represented by the IIP. In line with our observations, Schneider, Huprich, and Fuller [40] found two of the Critical Content components to correlate with the IIP scales: MOR, the interpretive meaning being morbid thoughts or feelings, and AG, indicating experienced aggression. In our study, however, the association of Critical Contents and the IIP was not found statistically significant in models adjusted for potential confounding factors, and thus the association was related to the biasing effect of psychiatric symptoms.

The large impact of psychiatric symptoms and the onset of the psychiatric disorder on the detected associations was a somewhat unexpected observation. Nevertheless, our observation is in line with the large number of previous investigations showing a significant association between psychiatric severity and the Rorschach EII-2 [8] [10], as well as between psychopathology and disordered thinking in the Rorschach [41]. Descriptively, the values of the EII-2 were found to differ in clinically meaningful ways. Accordingly, when the scores of the IIP, SPS, and QORS were the least problematic, the EII-2 most often indicated either no ego impairment or minimum impairment, applying interpretive ranges suggested by Viglione, Perry, and Meyer [7]. Respectively, when the scores of the IIP, SPS, and QORS were the most problematic, the EII-2 typically showed ego impairment, ranging from mild to severe impairment.

\subsection{Secondary Findings in Relation to the Personality Disorder Group}

As we expected, personality pathology appeared to modify some of the associations between the EII-2 and other measures. The EII-2 showed ego impairment most notably in patients with personality disorder. 
Personality disorder was found to modify the results regarding associations between the PHR and the IIP, as well as the associations between the EII- 2 and its subcomponent M- and the QORS. Higher values in the PHR were found to correlate with more reported interpersonal problems in the IIP within the personality disorder group. Thus, according to the IIP and PHR scores, high values for interpersonal problems and the PHR specifically accumulated among patients with personality disorder. This observation is in accordance with normative data and elaboration by Exner [25] that numerous PHR responses, reflecting unrealistic, damaged, or incomplete human representations, typically appear in protocols for individuals with personality disorder and maladaptive interpersonal behavior.

In models adjusted for potential confounders, the association between the EII-2 and the categorized QORS was significant among patients without personality disorder, indicating that a low level of object relations to be associated with greater ego impairment. However, the observed association between Mand QORS in the personality disorder group was in an unexpected direction, indicating more distortions in interpersonal perception among patients with the highest quality of object relations. M- responses have been demonstrated to be related to distorted perceptions of others [41], but have also been interpreted as indicating impairment of the thought process [7]. Our findings may reflect the fact that in the present study, within this context of relatively healthy persons seeking psychotherapy, even distorted M- responses may indicate the potential for mature interpersonal behaviors, i.e. the ability to be open-minded about one's relational concerns. Furthermore, this association might be a coincidental finding. Thus, future investigations are warranted to more specifically examine our unexpected finding of a discrepancy between the interview-based assessment and the Rorschach-based assessment of interpersonal difficulties.

\subsection{Methodological Issues}

We found the EII-2 to be more strongly associated with the interview-based assessment measures, the SPS and QORS, than with self-report measure, the IIP. Similarly, Diener et al. [8] observed a stronger association between the EII score and psychiatric severity assessed by researcher ratings (e.g., diagnosis-based rating of ego impairment), with weighted effect size of $r=0.45, p<0.001$, but a weaker association between the EII and psychiatric severity assessed by self-report ratings, with weighted effect size of $r=0.10, p=0.07$. More broadly, RCS scores in general have been observed to correlate more closely with externally assessed criteria (e.g., observer ratings and diagnoses) $(r=0.27)$ than with self-reported ratings $(r=0.08)$ [41]. This observation may be partly explained by a common finding that self-reported ratings, such as the IIP, may be more easily influenced by defensive efforts: either consciously reluctant reporting of interpersonal problems or unconsciously skewed or inaccurate ways of viewing oneself and interpersonal difficulties. Furthermore, interview-based assessments allow the inter- 
viewer to observe the patient's behavior in a situation encompassing ambiguity caused by open-ended questions, thus resembling the acquisition of the Rorschach protocol. More generally, previous data suggest that performance-based measures, i.e., the Rorschach, tap different domains of personality compared to introspective self-report and interview-based assessment measures, leading to mainly low correlations between the measures. Our findings partially support these suggestions.

The relatively large sample size and well-defined study group are the major strengths of this study. Therefore, we consider the observations of the present study to be generalizable to outpatient populations without severe personality pathology or psychosis. The QORS [14] and the IIP-64 [15] are well-known and widely used measures with demonstrated utility in the assessment of intrapsychic and interpersonal functioning. The SPS, as a new method, has been found to be a reliable and valid measure of psychological suitability for psychotherapy [1]. In our data, patients were medication-free, based on a one month washout period, when assessed, and medication thus had no impact on the results. In the present study sample, the reliability of the scoring of the EII-2 and its subcomponents was high [13].

There were also some limitations to this study. While the QORS and IIP categories comprised an equal number of participants, the SPS categories did not. Most of the patients were assessed as "suitable" in the SPS, and this may have led to the loss of some information and increased the risk of type II statistical errors. Nevertheless, we also examined the differences between continuous SPS values, which reduced the possible biasing effect due to categories of different sizes. As we compared the EII-2 and its subcomponents with the IIP total score, the results reflect the associations between the EII-2 and its subcomponents and the severity of interpersonal problems in general, whereas the specific nature of problems, based on the IIP subscales, was not utilized to avoid undue complexity in the analyses. Furthermore, the structure of the IIP subscales was mostly concentrated on the submissive hemisphere of the circumplex measure, and thus might not have given additional information [42]. Respectively, the analyses concerning the EII-2 and the SPS were limited to investigating the associations with the SPS total score.

Regarding the Rorschach method, both the limited validity and limited knowledge of the validity of some of the EII-2 subcomponents reduces the certainty of our study conclusions. Also, for the total EII-2 score, some problems in psychometric properties, e.g., excessive variability and positive skewness, have been reported by Viglione, Perry, Giromini, and Meyer [43]. Moreover, the somewhat ambiguous Rorschach variables and complicated and unpredictable effects of contextual factors on the interpretation of the variables adds to the uncertainty of the evidence. Likewise, specific psychological mechanisms, such as the denial of unwanted characteristics, may have had a more robust influence on some measures than others. More specifically, for example, the denial of interpersonal problems in the IIP may have contributed to good values for this method, while 
the problems in this respect may have been revealed in the Rorschach method via the PHR score or M- responses.

Men comprised a minority (24.4\%) of study population. Nevertheless, no significant Rorschach differences between women and men have been shown [44].

The number of responses (R) was associated with the EII-2. However, the detected association was rather modest, that is, weaker than the associations between the $\mathrm{R}$ and the EII-2 subscales. Moreover, the $\mathrm{R}$ is one subcomponent of the EII-2, and controlling for it was not therefore reasonable, as response productivity cannot conceptually be completely separated from personality characteristics and from the subject's orientation towards the assessment situation.

\section{Conclusion}

In conclusion, the purpose of this study was to acquire knowledge on a general level of the extent of convergence between the performance-based EII-2 measure and three measures of intrapsychic and interpersonal functioning. In our study, as expected, associations between dissimilar assessment methods, the Rorschach-derived EII-2 and its subcomponents and the SPS, IIP, and QORS, were relatively weak and often modified by psychiatric symptoms. As the specificity of the EII-2 as a measure of psychopathology remains rather vague, future research should be directed to its practical utility, e.g. whether it has incremental value as a predictor of the effectiveness of psychotherapy in comparison to other measures as predictors.

\section{References}

[1] Laaksonen, M.A., Lindfors, O., Knekt, P. and Aalberg, V. (2012) Suitability for Psychotherapy Scale (SPS) and Its Reliability, Validity, and Prediction. British Journal of Clinical Psychology, 51, 351-375. https://doi.org/10.1111/j.2044-8260.2012.02033.x

[2] Piper, W.E., Azim, H.F., McCallum, M. and Joyce, A.S. (1990) Patient Suitability and Outcome in Short-Term Individual Psychotherapy. Journal of Consulting and Clinical Psychology, 58, 475-481. https://doi.org/10.1037/0022-006X.58.4.475

[3] Valbak, K. (2004) Suitability for Psychoanalytic Psychotherapy: A Review. Acta Psychiatrica Scandinavica, 109, 164-178. https://doi.org/10.1046/j.1600-0447.2003.00248.x

[4] Ganellen, R.J. (2007) Assessing Normal and Abnormal Personality Functioning: Strengths and Weaknesses of Self-Report, Observer, and Performance-Based Methods. Journal of Personality Assessment, 89, 30-40. https://doi.org/10.1080/00223890701356987

[5] Meyer, G.J., Finn, S.E., Eyde, L.D., Kay, G.G., Moreland, K.L., Dies, R.R., Eisman, E.J., Kubiszyn, T.W. and Reed, G.M. (2001) Psychological Testing and Psychological Assessment: A Review of Evidence and Issues. American Psychologist, 56, 128-165. https://doi.org/10.1037/0003-066X.56.2.128

[6] Perry, W. and Viglione, D.J. (1991) The Ego Impairment Index as a Predictor of Outcome in Melancholic Depressed Patients Treated with Tricyclic Antidepressants. Journal of Personality Assessment, 56, 487-501. https://doi.org/10.1207/s15327752jpa5603_10 
[7] Viglione, D.J., Perry, W. and Meyer, G. (2003) Refinements in the Rorschach Ego Impairment Index Incorporating the Human Representational Variable. Journal of Personality Assessment, 81, 149-156. https://doi.org/10.1207/S15327752JPA8102_06

[8] Diener, M.J., Hilsenroth, M.J., Shaffer, S.A. and Sexton, J.E. (2011) A Meta-Analysis of the Relationship between the Rorschach Ego Impairment Index (EII) and Psychiatric Severity. Clinical Psychology and Psychotherapy, 18, 464-485. https://doi.org/10.1002/cpp.725

[9] Adrian, C. and Kaser-Boyd, N. (1995) The Rorschach Ego Impairment Index in Heterogeneous Psychiatric Patients. Journal of Personality Assessment, 65, 408-414. https://doi.org/10.1002/cpp.725

[10] Hilsenroth, M.J., Eudell-Simmons, E.M, DeFife, J.A. and Charnas, J.W. (2007) The Rorschach Perceptual-Thinking Index (PTI): An Examination of Reliability, Validity, and Diagnostic Efficiency. International Journal of Testing, 7, 269-291. https://doi.org/10.1080/15305050701438033

[11] Hathaway, S.R. and McKinley, J.C. (1943) The Minnesota Multiphasic Personality Schedule. University of Minnesota Press, Minneapolis.

[12] Dawes, R.B. (1999) Two Methods for Studying the Incremental Validity of a Rorschach Variable. Psychological Assessment, 11, 297-302. https://doi.org/10.1037/1040-3590.11.3.297

[13] Valkonen, H., Lindfors, O. and Knekt, P. (2012) Association between the Rorschach Ego Impairment Index and the Level of Personality Organization Interview Assessment in Depressive and Anxiety Disorder Patients. Psychiatry Research, 200, 849-856. https://doi.org/10.1016/j.psychres.2012.05.012

[14] Azim, H.F., Piper, W.E., Segal, P.M., Nixon, G.W. and Duncan, S.C. (1991) The Quality of Object Relations Scale. Bulletin of the Menninger Clinic, 55, 323-343.

[15] Horowitz, L.M., Alden, L.E., Wiggins, J.S. and Pincus, A.L. (2000) Inventory of Interpersonal Problems Manual. The Psychological Corporation, San Antonio.

[16] Laaksonen, M.A., Knekt, P. and Lindfors, O. (2013) Psychological Predictors of the Recovery from Mood or Anxiety Disorder in Short-Term and Long-Term Psychotherapy during a 3-Year Follow-Up. Psychiatry Research, 208, 162-173. https://doi.org/10.1016/j.psychres.2012.09.053

[17] Laaksonen, M.A., Knekt, P., Sares-Jäske, L. and Lindfors, O. (2013) Psychological Predictors on the Outcome of Short-Term Psychodynamic Psychotherapy and Solution-Focused Therapy in the Treatment of Mood and Anxiety Disorder. European Psychiatry, 28, 117-124. https://doi.org/10.1016/j.eurpsy.2011.12.002

[18] Lindfors, O., Knekt, P. and Virtala, E. (2013) Quality of Object Relations Modifies the Effectiveness of Short- and Long-Term Psychotherapy on Self-Concept. Open Journal of Psychiatry, 3, 345-350. https://doi.org/10.4236/ojpsych.2013.34036

[19] Piper, W.E., Ogrodniczuk, J.S. and Joyce, A.S. (2004) Quality of Object Relations as a Moderator of the Relationship between Pattern of Alliance and Outcome in Short-Term Individual Psychotherapy. Journal of Personality Assessment, 83, 345-356. https://doi.org/10.1207/s15327752jpa8303_15

[20] Puschner, B., Kraft, S. and Bauer, S. (2004) Interpersonal Problems and Outcome in Outpatient Psychotherapy: Findings from a Long-Term Longitudinal Study in Germany. Journal of Personality Assessment, 83, 223-234. https://doi.org/10.1207/s15327752jpa8303_06

[21] Renner, F., Jarrett, R.B., Vittengl, J.R., Barrett, M.S., Clark, L.A. and Thase, M.E. (2012) Interpersonal Problems as Predictors of Therapeutic Alliance and Symptom 
Improvement in Cognitive Therapy for Depression. Journal of Affective Disorders, 138, 458-467. https://doi.org/10.1016/j.jad.2011.12.044

[22] Archer, R.P. and Krishnamurthy, R. (1993) A Review of MMPI and Rorschach Interrelationships in Adult Samples. Journal of Personality Assessment, 61, 277-293. https://doi.org/10.1207/s15327752jpa6102_9

[23] Knekt, P. and Lindfors, O. (2004) A Randomized Trial of the Effect of Four Forms of Psychotherapy on Depressive and Anxiety Disorders. Design, Methods, and Results on the Effectiveness of Short-Term Psychodynamic Psychotherapy and Solution-Focused Therapy during a One-Year Follow-Up. Studies in Social Security and Health 77. The Social Insurance Institution, Helsinki.

[24] Knekt, P., Lindfors, O., Härkänen, T., Välikoski, M., Virtala, E., Laaksonen, M.A., Marttunen, M., Kaipainen, M. and Renlund, C. (2008) Randomized Trial on the Effectiveness of Long- and Short-Term Psychodynamic Psychotherapy and Solution-Focused Therapy on Psychiatric Symptoms during a 3-Year Follow-Up. Psychological Medicine, 38, 689-703. https://doi.org/10.1017/S003329170700164X

[25] Exner, J.E. (2003) The Rorschach: A Comprehensive System. Vol. 1, 4th Edition, Basic Foundations, Wiley, New York.

[26] Kernberg, O.G. (1981) Structural Interviewing. Psychiatric Clinics of North America, 4, 169-195.

[27] Lindfors, O., Knekt, P., Virtala, E. and Haaramo, P. (2013) Concurrent Validity of the Quality of Object Relations Scale (QORS) in Relation to Proxy Assessment of the Theoretical Scale Constituents. Psychopathology, 46, 111-119.

https://doi.org/10.1159/000339385

[28] Viglione, D.J., Perry, W., Jansak, D., Meyer, G. and Exner, J.E. (2003) Modifying the Rorschach Human Experience Variable to Create the Human Representational Variable. Journal of Personality Assessment, 81, 64-73. https://doi.org/10.1207/S15327752JPA8101_06

[29] Janson, H. (2008) Calculating and Eeporting Rorschach Intercoder Agreement. Annual Meeting of the Society for Personality Assessment, New Orleans, March 2008.

[30] American Psychiatric Association (1994) Diagnostic and Statistical Manual of Mental Disorders. 4th Edition, American Psychiatric Association, Washington DC.

[31] Derogatis, L.R., Lipman, R.S. and Covi, L. (1973) SCL-90: An Outpatient Psychiatric Rating Scale-Preliminary Report. Psychopharmacology Bulletin, 9, 13-28.

[32] Beck, A.T., Ward, C.H., Mendelson, M., Mock, J. and Erbaugh, J. (1961) An Inventory for Measuring Depression. Archives for General Psychiatry, 4, 561-571. https://doi.org/10.1001/archpsyc.1961.01710120031004

[33] Cohen, J. and Cohen, P. (1975) Applied Multiple Regression/Correlation Analysis for the Behavioral Sciences. Lawrence Erlbaum Associates, Inc., Hillsdale.

[34] Rothman, K.J. and Greenland, S. (1998) Modern Epidemiology. Lippincott, Williams and Wilkins, Philadelphia.

[35] Breslow, N.E. and Day, N. (1980) Statistical Methods in Cancer Research. The Analysis of Case-Control Studies. Vol. 1, IARC, Lyon.

[36] Lee, J. (1981) Covariance Adjustment of Rates Based on the Multiple Logistic Regression Model. Journal of Chronic Diseases, 34, 415-426. https://doi.org/10.1016/0021-9681(81)90040-0

[37] SAS Institute Inc. (2007) SAS/STAT User's Guide, Version 9.1. SAS Institute Inc., Cary. 
[38] Biagiarelli, M., Roma, P., Comparelli, A., Andraos, M.P., Di Pomponio, I., Corigliano, V., Curto, M., Masters, G.A. and Ferracuti, S. (2015) Relationship between the Rorschach Perceptual Thinking Index (PTI) and the Positive and Negative Syndrome Scale (PANSS) in Psychotic Patients: A Validity Study. Psychiatry Research, 225, 315-321. https://doi.org/10.1016/j.psychres.2014.12.018

[39] Nygren, M. (2004) Rorschach Comprehensive System Variables in Relation to Assessing Dynamic Capacity and Ego Strength for Psychodynamic Psychotherapy. Journal of Personality Assessment, 83, 277-292.

https://doi.org/10.1207/s15327752jpa8303_10

[40] Schneider, R.B., Huprich, S.K. and Fuller, K.M. (2008) The Rorschach and the Inventory of Interpersonal Problems. Rorschachiana, 29, 3-24.

https://doi.org/10.1027/1192-5604.29.1.3

[41] Mihura, J.L., Meyer, G.J., Dumitrascu, N. and Bombel, G. (2013) The Validity of Individual Rorschach Variables: Systematic Reviews and Meta-Analyses of the Comprehensive System. Psychological Bulletin, 139, 548-605.

https://doi.org/10.1037/a0029406

[42] Ollila, P., Knekt, P., Heinonen, E. and Lindfors, O. (2016) Patients' Pre-Treatment Interpersonal Problems as Predictors of Therapeutic Alliance in Long-Term Psychodynamic Psychotherapy. Psychiatry Research, 241, 110-117.

https://doi.org/10.1016/j.psychres.2016.04.093

[43] Viglione, D.J., Perry, W., Giromini, L. and Meyer, G.J. (2011) Revising the Rorschach Ego Impairment Index to Accommodate Recent Recommendations about Improving Rorschach Validity. International Journal of Testing, 11, 349-364. https://doi.org/10.1080/15305058.2011.589019

[44] Meyer, G.J., Giromini, L., Viglione, D.J., Reese, J.B. and Mihura, J. (2015) The Association of Gender, Ethnicity, Age, and Education with Rorschach Scores. Assessment, 22, 46-64. https://doi.org/10.1177/1073191114544358 